\title{
Knowledge and Attitudes of Health Care Providers and the Population about Rabies in Sokone Health District, Senegal
}

\author{
Khadim Niang1,2, Jean A. D. Tine², Ahmadou B. Ndao³, Fatoumata B. Diongue², Amadou I. Diallo², \\ Adama Faye ${ }^{2}$, Papa Ndiaye ${ }^{1}$, Anta Tal-Dia ${ }^{2}$ \\ ${ }^{1}$ Public Health Department, Gaston Berger University (UGB), Saint-Louis, Senegal \\ ${ }^{2}$ Institut de Santé et Développement, Cheikh Anta Diop University, Dakar, Senegal \\ ${ }^{3}$ Chief Medical Officer of Sokone Health District, Fatick Region, Senegal \\ Email:khadimniang@outlook.com
}

How to cite this paper: Niang, K., Tine, J.A.D., Ndao, A.B., Diongue, F.B., Diallo, A.I., Faye, A., Ndiaye, P. and Tal-Dia, A. (2020) Knowledge and Attitudes of Health Care Providers and the Population about Rabies in Sokone Health District, Senegal. Open Journal of Preventive Medicine, 10 , 63-71.

https://doi.org/10.4236/ojpm.2020.104004

Received: January 2, 2020

Accepted: April 23, 2020

Published: April 26, 2020

Copyright $\odot 2020$ by author(s) and Scientific Research Publishing Inc. This work is licensed under the Creative Commons Attribution International License (CC BY 4.0).

http://creativecommons.org/licenses/by/4.0/ (c) (i) Open Access

\begin{abstract}
Rabies is still a deadly disease, but it is $100 \%$ preventable through vaccination. In 2016, Senegal notified 1214 cases of dog bites. In the same year, the district of Sokone recorded 50 cases of dog bites, of which $31.2 \%$ of the cases were notified in the region of Fatick. The objective of this study is to assess the level of knowledge, attitudes and practices of communities and healthcare providers when faced with a case of exposure to rabies in Sokone health district. This quantitative estimation study is of a descriptive cross-sectional type, which took place during the third quarter of 2017. It targeted the community and health care providers in the Sokone health district. Three-stage cluster sampling was carried out in the community. The recruitment of healthcare providers has been comprehensive. A questionnaire was administered to the community in the form of individual interviews and another questionnaire was sent to health care providers in the form of self-administration. Knowledge, attitude and practice rating grids were developed for the two categories of interviewees. Data entry and analysis was done with Epi Info 3.5.3 software and R 3.3.1. Out of 813 community members surveyed, $6.8 \%$ had already been bitten by an animal. A good level of knowledge about rabies was found in $22.4 \%$ of the community members. The attitude to a bite was correct for 94.1\%. Of the 38 healthcare providers surveyed, only 5.6\% had a good understanding of rabies. No provider knew the indications for rabies vaccination and the post-exposure vaccination schedule. In the Sokone health district, communities knew little about rabies. Healthcare providers who are supposed to inform and supervise them in the fight against rabies know less about it. Strengthening the skills of healthcare staff in dealing with bites exposing them
\end{abstract}


to rabies is of urgency in the Sokone health district.

\section{Keywords}

Rabies, Zoonosis, Neglected Tropical Disease, Bites, Senegal

\section{Introduction}

Rabies is one of the oldest known diseases. In the third millennium BC, the Laws of Eshunna in Babylon stated: "If the fact that a dog is mad is brought to the attention of its owner, if the dog is not kept at home and bites someone causing his death, the owner will have to pay 40 silver coins. If he bites a slave causing his death, he will have to pay 15 silver coins". And yet, more than 125 years after the discovery of the rabies vaccine by Louis Pasteur, human rabies still remains a neglected tropical disease and poses a public health problem [1].

Human rabies is a serious disease; once symptoms appear, it is always fatal [2]. It is responsible for 59,000 deaths and $90 \%$ of cases occur in Africa and Asia. The dog is responsible for $99 \%$ of rabies cases and the victims are children under 15 years of age in $30 \%$ to $50 \%$ of cases [3].

In Senegal, since June 2008, bites exposed to rabies have been under weekly epidemiological surveillance and technical sheets have been drawn up. Bite cases are regularly included in the weekly epidemiological bulletin issued by the prevention department of the Ministry of Health and Social Action [4].

In 2016, through weekly epidemiological bulletins, Senegal notified 1445 cases of animal bites exposing them to rabies. Of the biting animals, 1214, or $84 \%$, were dogs. In the same year 2016, the Fatick region notified 133 cases of dog bites, 50 (31.2\%) of which were notified by the Sokone health district [5].

Despite this risk of rabies transmission in humans, this disease remains in the lot of neglected tropical diseases (NTD). Thus, no studies on the knowledge, attitudes and practices of populations and human health providers regarding dog bites have been found in our literature review, both in Senegal and Africa. The rabies studies are mainly carried out by veterinarians on the vaccination of dogs, but also by doctors on the symptomatic rabies. This situation has led us to question the knowledge, attitudes and practices of populations and health care providers about rabies-exposing bites.

\section{Methodology}

\subsection{Study Framework}

Senegal is situated in the western-most part of the African continent on the Atlantic Ocean where Europe, Africa and the Americas converge and at the crossroads of major air and shipping routes.

The Sokone health district was established in 1991. It is located in the Fatick region, more precisely in the department of Foundiougne. It occupies an area of 
$1068 \mathrm{~km}^{2}$ and has a population of 167,401 inhabitants.

Post-exposure management of rabies is available at the center and district health posts, however no communication activity has been conducted on the subject by the health district. Animal health is managed by private veterinarians who are much more active with cattle and sheep, and the veterinary surgeon of the Ministry of Livestock. Dogs are vaccinated at the request of owners and stray dogs are found straying in all neighborhoods and villages of the district.

\subsection{Type and Period of Study}

It is a cross-sectional, descriptive survey. It took place during the third quarter of 2017.

\subsection{Study Population and Sampling Protocol}

This study included a household component targeting population, and a structures component that targeted health care providers.

For the household component, all persons aged 15 years and over and residing in the health district area were eligible. All providers providing care services (nurses, midwives, doctors) from district health facilities were eligible for this study.

The criteria for non-inclusion were common to both strands. It was absence of the targeted person, and the refusal to participate. The district medical officer, who participated in developing the protocol and conducting the survey, was not included.

The recruitment of healthcare providers has been comprehensive. For the household component, the calculation of the sample size was done with the Schwartz formula $\left(\mathrm{n}=\varepsilon^{2} \times \mathrm{p} \times \mathrm{q} / \mathrm{i}^{2}\right)$ with $\varepsilon=1.96$, an expected frequency of 0.5 and an accuracy of 0.05 [6]. A cluster effect of 2 was taken into consideration in the calculation. The calculated size has been rounded to 810 to have 81 clusters of 10 people.

To identify the statistical units of the household component, a three-stage cluster survey was conducted. On a sampling frame comprising the different districts and villages of the health district with their population, a stratified random distribution with proportional allocation of the 81 clusters to be surveyed was made. At the level of each selected cluster, concessions were selected progressively according to the itinerary's method. Within each selected concession, a household was drawn by basic survey. All persons fulfilling the selection criteria within the selected household were included and surveyed.

\subsection{Collection of Data}

Two questionnaires were developed for this study. The first was intended for healthcare providers and included questions in the following headings: Identification of the respondent, Knowledge of rabies, Assessment of the level of rabies risk, Post-exposure treatment, Epidemiological surveillance of bites exposing 
people to rabies, Prevention of rabies. The questionnaire was self-administered. It was just handed over to the service provider, then recovered as soon as it was filled. A team of two investigators visited the district health structures for this collection.

For the household component, a second questionnaire was developed according to the objectives of the study and inspired by the elements of the documentary review. This questionnaire included the following headings: Identification of the respondent, Experience in relation to bites and rabies, Knowledge of rabies, how to deal with a case of animal bite. A team of 10 interviewers conducted the collection of this data at the selected household's level.

The questionnaires were drawn up so as not to suggest expected answers, in order not to influence the respondent.

\subsection{Data Enter and Analysis}

The data collected was entered with the Epi info 7.2. software. After cleaning and data management, univariate analyzes were carried out using the same software.

To study knowledge and practices, new variables have been created to define the level [7]. Were considered to have a good level of knowledge, the individuals having given a good answer to at least $85 \%$ of the questions. For attitudes, the right level was defined by a correct answer to at least $85 \%$ of the questions (Table 1).

The description of the qualitative variables was done through frequency measurements, that of the quantitative variables called for the calculation of arithmetic means with their standard deviation.

\subsection{Ethical Considerations}

The consent of the people surveyed was previously obtained through the information form. Consent was given by the opening of the questionnaire and its filling which was done remotely on a voluntary basis.

Respondents were informed of the objectives and constraints of the study, of their rights to refuse to participate in the study or to leave it at any time. Anonymity and confidentiality were respected.

\section{Results}

\subsection{Among Community Members}

In this study, 813 community members were surveyed. Their average age was 29.1 years, with a standard deviation of 13.2 years. The minimum age was 15 and the maximum age 76 years.

The sex ratio M/F was 1.5. The Muslim religion was predominant with a proportion of $91.1 \%$. The sample included $82.3 \%$ of students. In relation to occupations, $61.3 \%$ had an income-generating activity, $34.1 \%$ were pupils/students (Table 2).

$6.8 \%$ of those surveyed in the community were once bitten by an animal other 
Table 1. Questions asked of both targets about their knowledge and attitudes to rabies-exposing bites.

\begin{tabular}{|c|c|}
\hline Areas & Targets/Questions asked \\
\hline Knowledge & $\begin{array}{l}\text { Healthcare providers } \\
\text { - What type of microbe is responsible for rabies? } \\
\text { - How long is human rabies incubation? } \\
\text { - What bite makes you suspect rabies? } \\
\text { - How does declared human's rabies evolve? } \\
\text { - Citing the different reservoirs/vectors of rabies } \\
\text { - Citing the steps of managing a rabies-exposing bite } \\
\text { - Citing rabies risk categories following an animal bite } \\
\text { - Describe the timing of the two post-exposure rabies vaccination protocols } \\
\text { - } \quad \text { Whailable in Senegal } \\
\text { - How much does the dose of rabies vaccine cost? } \\
\text { Community members } \\
\text { - What are the risks to a person bitten by an animal? } \\
\text { - Citing at least two symptoms of rabies in humans } \\
\text { - Citing the routes of transmission of rabies to humans } \\
\text { - What is the evolution of rabies reported in humans? }\end{array}$ \\
\hline $\begin{array}{l}\text { Attitudes, } \\
\text { practices and } \\
\text { management } \\
\text { tools }\end{array}$ & $\begin{array}{l}\text { Healthcare providers } \\
\text { - Do you systematically contact the veterinary services in the event of a bite } \\
\text { exposing to rabies? } \\
\text { - Do you have contact with at least one veterinarian in your work area? } \\
\text { - Do you have rabies exposure notices } \\
\text { Community members } \\
\text { - What would be your conduct in case of a bite by a stray dog }\end{array}$ \\
\hline
\end{tabular}

Table 2. Characteristics of community investigators $(n=813)$.

\begin{tabular}{lcc}
\hline \multicolumn{1}{c}{ Parameters } & Absolute frequencies (n) & Relative frequencies (\%) \\
\hline Gender & 323 & 39.7 \\
Female & 490 & 60.3 \\
Male & & \\
Religion & 69 & 8.5 \\
Christian & 741 & 91.1 \\
Muslim & 3 & 0.4 \\
Others & & \\
Level of education & 144 & 17.7 \\
Not in school & 236 & 29.0 \\
Primary & 360 & 44.3 \\
Secondary & 73 & 9.0 \\
Higher & & \\
Occupational & 277 & 34.1 \\
Student & 154 & 18.9 \\
Trading & 76 & 9.3 \\
Agriculture & 49 & 6.0 \\
Official & 220 & 27.1 \\
Other activities & 37 & 4.6 \\
No income-earning activity & & \\
\hline
\end{tabular}


than a snake. They were dogs in $67.3 \%$ of the cases and donkeys in $18.2 \% .28 .6 \%$ of those surveyed have already witnessed the bite of a third person by an animal other than a snake. It was a dog in $88.4 \%$, a donkey in $6.9 \%$, a horse in $3.9 \%$ of the cases. Confronted with an animal bite, $94.1 \%$ of the respondents took the bitten person directly to a health facility (Table 3 ).

Good knowledge of rabies was found in 182 people in the community, or $22.4 \%$. The fatal development of symptomatic rabies was known to $43.8 \%$ of the respondents. However, only $3.1 \%$ were aware of the modes of rabies transmission (all warm-blooded animals), most of which pointed only to the dog (Table 4).

\subsection{At Healthcare Providers}

In this study, 38 healthcare providers directly involved in the management of rabies-prone bites were investigated. They were midwives (36.8\%), nurses (28.9\%) and nursing assistants (34.3\%). Apart from the District Chief doctor, the doctor at the health center was not available at the time of the collection phase. Thus, of the 48 targeted providers, a proportion of $79.1 \%$ could be questioned.

The average length of service providers surveyed was 7.4 years, with a standard deviation of 5.0 and a median of 7.0 years. The minimum seniority was less than one year and the maximum seniority 28 years.

Table 3. Animal bite experiment $(n=813)$.

\begin{tabular}{lcc}
\hline \multicolumn{1}{c}{ Parameters } & $\begin{array}{c}\text { Absolute frequencies } \\
\text { (n) }\end{array}$ & $\begin{array}{c}\text { Relative frequencies } \\
\text { (\%) }\end{array}$ \\
\hline History of personal bite per animal & 55 & 6.8 \\
Yes & 758 & 93.2 \\
No & & \\
Animal bite assistance experience & 232 & 28.6 \\
Yes & 581 & 71.5 \\
No & & \\
Attitude to a dog bite case & 765 & 94.1 \\
Go directly to the hospital & 48 & 5.9 \\
Go to the traditional healer & & \\
\hline
\end{tabular}

Table 4. Good knowledge of those surveyed in the community $(\mathrm{n}=813)$.

\begin{tabular}{lcc}
\hline \multicolumn{1}{c}{ Parameters } & $\begin{array}{c}\text { Absolute frequencies } \\
\text { (n) }\end{array}$ & $\begin{array}{c}\text { Relative frequencies } \\
\text { (\%) }\end{array}$ \\
\hline Risk of infection following a bite & 323 & 39.7 \\
Symptoms of rabies & 80 & 9.8 \\
Modes of rabies transmission & 25 & 3.1 \\
Evolution of symptomatic rabies & 356 & 43.8 \\
Bite prevention methods & 83 & 10.2 \\
\hline
\end{tabular}


Three providers declared that they had been trained (one for 1 day and two for 2 days) on the management of bites exposed to rabies during the three years preceding the survey.

Only two providers, or 5.3\%, had good knowledge on the management of bites and rabies. These were the two providers who received two-day training on the treatment of bites exposed to rabies. The best-known aspects of the providers were the evolution of symptomatic rabies (death) and the type of microbe implicated (virus). The indications for vaccination and post-exposure vaccination protocols were not well known to any of the providers surveyed (Table 5).

Notification forms were available from $73.7 \%$ of providers questioned, contrary to contact with veterinarians available only in $26.3 \%$ of cases. $42.1 \%$ of providers declared that they systematically contact the veterinarian in the event of an animal bite.

\section{Discussion and Comments}

Rabies is a public health problem, mainly in Asia and Africa. However, it remains neglected still neglected as evidenced by the scantiness of publications on the subject in sub-Saharan Africa [8]. In Senegal, the literature focuses more on rabies symptoms and animal rabies. To our knowledge, this study is the first to assess the knowledge of populations and primary care providers on the subject.

In our study, $6.8 \%$ of the respondents declared that they had been bitten by an animal and $28.6 \%$ declared that they had already witnessed the bite of a third person by an animal. This indicates an increased risk of contamination of animal zoonoses.

The biting animal was mainly represented by the dog and the cat, which is corroborated by Ndiaye [9] who found that $82.5 \%$ of the bites exposed to rabies were of canine origin, this through a series from 2011 to 2015. This high proportion of canine bites constitutes a real danger since more than $90 \%$ of cases of human rabies result from the transmission of the disease to humans by a dog

Table 5. Good knowledge of health care providers $(\mathrm{n}=38)$.

\begin{tabular}{lcc}
\hline \multicolumn{1}{c}{ Parameters } & $\begin{array}{c}\text { Absolute frequencies } \\
(\mathbf{n})\end{array}$ & $\begin{array}{c}\text { Relative frequencies } \\
\text { (\%) }\end{array}$ \\
\hline Type of microbe incriminated & 17 & 44.7 \\
Reservoirs/vectors & 2 & 5.3 \\
Incubation time & 3 & 7.9 \\
Symptomatology of human rabies & 1 & 2.6 \\
Evolution of symptomatic rabies & 20 & 52.6 \\
Vaccination indications & 0 & 0.0 \\
Post-exposure vaccination protocols & 0 & 0.0 \\
Rabies prevention measures & 1 & 2.6 \\
Bite notification circuit & 9 & 23.7 \\
Cost of a dose of rabies vaccine & 6 & 15.8 \\
\hline
\end{tabular}


[10]. Added to this is the fact that the non-vaccination of companion dogs and the proliferation of stray dogs remains a major problem in the fight against rabies in Senegal [11].

Only $22.4 \%$ of the community members interviewed had a good knowledge of rabies and the management of bites exposing them to rabies. This could be due to the rarity of rabies cases in the community. In fact, despite recurrent bites in the Sokone district, the last case of symptomatic rabies dates back to 2012 [12]. This low level of knowledge is also due to the rarity of communication activities on bites exposed to rabies [11], as well as symptomatic rabies. No awareness raising or social mobilization activity is observed outside the celebration of the international rabies day.

The health care providers responsible for caring for and informing communities about rabies prevention actions are poorly trained and have low levels of knowledge. Only 5.3\% had good knowledge of rabies. Preventive and post-exposure rabies vaccination are the key elements in preventing the transmission of rabies in humans. However, none of the providers questioned knew the indications for this vaccination and its schedule. This lack of control over vaccination leads to non-compliance with management protocols in the event of exposure [11].

The management of a bite exposed to rabies requires examination, or even observation of the biting animal by the veterinarian. However, only $42.1 \%$ of the healthcare providers questioned declared that they systematically called the veterinarian in the event of an animal bite. This stems from the weak relationship between animal health and human health, and the lack of implementation of the concept One health in health policies in Senegal [4].

\section{Conclusion}

Neglect of rabies remains a reality. This study highlighted a lack of training, and as a corollary of knowledge of health care providers in the prevention and management of bites exposed to rabies. Although they behave correctly when bitten, populations exposed to animal bites also have very little knowledge of rabies prevention. There is an urgent need to strengthen the skills of healthcare providers in the Sokone health district in terms of taking care of animal bites and to set up an integrated rabies control system built around the concept One Health.

\section{Conflicts of Interest}

The authors declare no conflicts of interest regarding the publication of this paper.

\section{References}

[1] Bourhy, H., Dautry-Varsat, A., Hotez, P.J. and Salomon, J. (2010) Rabies, Still Neglected after 125 Years of Vaccination. PLOS Neglected Tropical Diseases, 4, e839. https://doi.org/10.1371/journal.pntd.0000839

[2] Collège des universitaires de maladies infectieuses et tropicales (CMIT) (2004) E. 
PILLY-Maladies infectieuses et tropicales. 22ème Ed., France.

[3] Organisationmondiale de la santé, Bureau régional de l'Afrique (2013) Plan stratégique pour la luttecontre les maladies tropicalesnégligées dans la Régionafricaine 2014-2020. OMS Afro, 32 p.

[4] Faye, C. (2015) Contribution à unemeilleure implication des secteursconcernés par le contrôle de la rage dans le contexte de la luttecontre les maladies tropicalesnégligées (MTN) au Sénégal. CESAG Santé. MBA gestion des programmes de santé. 24ème promotion, $116 \mathrm{p}$.

[5] Direction de la Prévention (2016) Bulletin épidémiologiquehebdomadaire (BEH), 52ème semaine. Surveillance intégrée des maladies et riposte. Ministère de la Santé et de l'ActionSociale. Dakar, $4 \mathrm{p}$.

[6] Ardilly, P. (2006) Les techniques de sondage. Editions TECHNIP, 675 p.

[7] Essi, M.J., Njoya, O. and L'enquête, C.A.P. (2013) (Connaissances, Attitudes, Pratiques) en recherche médicale. Point de vue. Health Sciences and Diseases. 14.

[8] Sambo, M., Lembo, T., Cleaveland, S., Ferguson, H.M., Sikina, L., Simon, C., et al. (2014) Knowledge, Attitudes and Practices (KAP) about Rabies Prevention and Control: A Community Survey in Tanzania. PLOS Neglected Tropical Diseases, 8 , e3310. https://doi.org/10.1371/journal.pntd.0003310

[9] Ndiaye, A. (2015) Étude des caractéristiquessociodémographiquesthérapeutiques et de suivi des cas de morsuresexposant a la rage au Sénégal 2011-2015 [Thèse de Médecine]. UniversitéCheikh Anta Diop de Dakar, Faculté de Médecine, de pharmacie et d'odontostomatologie.

[10] Akakpo, A.J., Bomarel, P., Sarradin, P., Leye, S.M. and Aambedji, R. (1990) Socio-éthnologie et rôle du chien dans le département de Pikine (zone suburbaine de Dakar-Sénégal). Dakar Medical, 35, 99-104.

[11] Direction de la luttecontre la maladie. Plan stratégique de luttecontre les MTN 2016-2020. Ministère de la santé et de l'actionsociale [Sénégal].

[12] Équipe cadre du district sanitaire de Sokone (2013) Rapport du district Sokone 2012. District sanitaire de Sokone, Fatick. 